\title{
Correction to: Bulk Ring-Opening Polymerization of $\varepsilon$-Caprolactone by Zeolitic Imidazolate Framework
}

\author{
Farah Naz $^{1,2} \cdot$ Fatima Mumtaz $^{5} \cdot$ Somboon Chaemchuen ${ }^{1,4} \cdot$ Francis Verpoort $^{1,3,4,6}$
}

Published online: 25 June 2019

๑) Springer Science+Business Media, LLC, part of Springer Nature 2019

\section{Correction to: Catalysis Letters (2019) 149:2132-2141 https://doi.org/10.1007/s10562-019-02816-5}

An error appeared in our paper entitled "Bulk Ring-Opening Polymerization of $\varepsilon$-Caprolactone by Zeolitic Imidazolate Framework" published in Catalysis Letters. The wrong version of Fig. 7 has been used in the article. The corrected Fig. 7 is shown below.

Publisher's Note Springer Nature remains neutral with regard to jurisdictional claims in published maps and institutional affiliations.

\section{Somboon Chaemchuen}

sama_che@hotmail.com

$\triangle$ Francis Verpoort

francis.verpoort@ghent.ac.kr

1 Laboratory of Organometallic, Catalysis and Ordered Materials, State Key Laboratory of Advanced Technology for Materials Synthesis and Processing, Wuhan University of Technology, Wuhan 430070, People's Republic of China

2 School of Materials Science and Engineering, Wuhan University of Technology, Wuhan 430070, People's Republic of China
3 College of Arts and Science, Khalifa University of Science and Technology, PO Box 127788, Abu Dhabi, UAE

4 National Research Tomsk Polytechnic University, Lenin Avenue 30, Tomsk, Russian Federation 634050

5 CAS Key Laboratory of Soft Matter Chemistry, Department of Polymer Science and Engineering, University of Science and Technology of China, Hefei 230026, People's Republic of China

6 Center for Environmental and Energy Research (CEER), Ghent University Global Campus, 119 Songdomunhwa-Ro, Yeonsu-Gu, Incheon 406-840, South Korea 


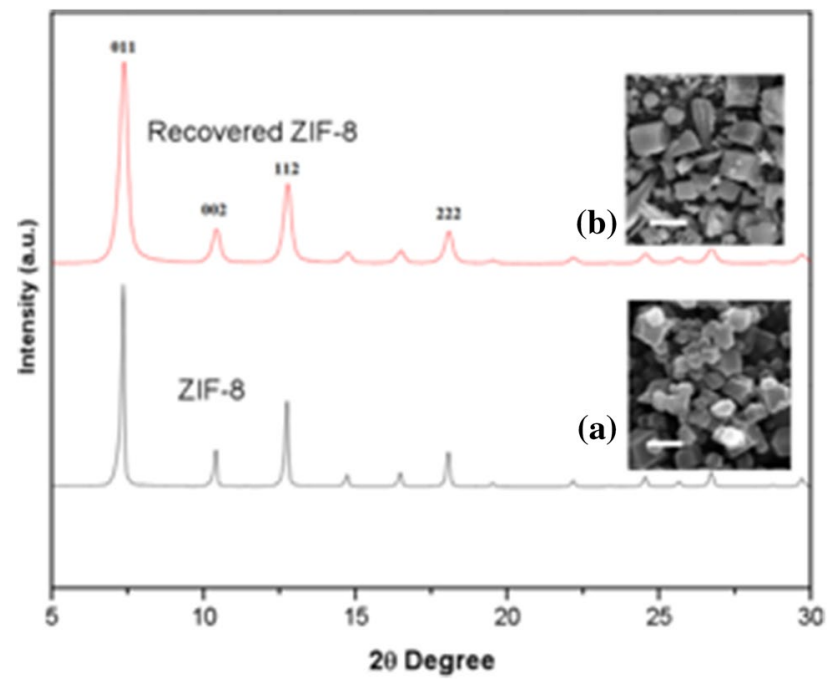

Fig. 7 Powder X-ray diffraction patterns of ZIF-8 (before use) and recovered ZIF-8 (after 3rd cycle). a SEM pictures of ZIF-8 (scale bar: $2 \mu \mathrm{m}), \mathbf{b}$ SEM micrographs of recovered ZIF-8 $(1 \mu \mathrm{m})$ 